\title{
2ECRET'-7)
}

\section{VALIDATION OF A NOVEL QUESTIONNAIRE TO SCREEN MIGRAINE IN YOUNG PATIENTS WITH ISCHEMIC STROKE AND STROKE-FREE CONTROLS}

\author{
Nicolas Martinez-Majander, MD; Ville Artto, MD, PhD1; Lauri Soinne, MD, PhD'; Turgut Tatlisumak, MD, PhD1,2; Jukka \\ Putaala, MD, PhD'; Mikko Kallela, MD,PhD'
}

${ }^{1}$ Clinical Neurosciences, Department of Neurology, University of Helsinki and Department of Neurology, Helsinki University Hospital, Finland; 'Department of Clinical Neuroscience, Institute of Neuroscience and Physiology, The Sahlgrenska Academy at University of Gothenburg, and Department of Neurology, Sahlgrenska University Hospital, Gothenburg, Sweden.

\section{Introduction}

Worldwide, approximately 1.3 million annual ischemic strokes occur prematurely in adults aged 18 to 49 years. ${ }^{1}$ Of these, up to $50 \%$ can be regarded as cryptogenic. ${ }^{2}$

Migraine, especially migraine with aura, is a well-known risk factor for ischemic stroke (IS) in the young. ${ }^{3}$ We designed a structured and concise questionnaire for screening both migraine with aura (MA) and without aura (MO) for a research setting, and conducted a validation study including both young patients with IS and stroke-free control subjects.

\section{Methods}

First, we prospectively enrolled patients aged between 18-49 years with a first-ever imaging-positive IS and age- and sex-matched strokefree controls in an ongoing multicenter case-control SECRETO study (NCTo1934725). ${ }^{4}$ Etiology of each IS was cryptogenic. Second, we performed screening of migraine using the questionnaire including 13 screening questions (Figure 1). Third, a clinical diagnosis of migraine was done by an independent experienced senior headache-neurologist based on International Headache Society (IHS) criteria, blinded to participant status and clinical data. We used Cohen's kappa statistics to measure agreement between these two methods and to validate the novel questionnaire. We considered kappa-value over 0.75 as an excellent agreement.

\section{Results}

We included 50 patients (median age 41 years; 23 women) and 50 control subjects (median age 42 years; 24 women). Based on both the migraine-specific questionnaire and clinical evaluation, 22 (44\%) patients had MA, with an inter-rater agreement (Cohen's kappa) of o.84. Furthermore, 4 (8\%) vs. 6 (12\%) patients were diagnosed with MO, with a kappa of 0.78 . Kappa value for any type of migraine was o.84. Corresponding values for controls based on the questionnaire vs. clinical evaluation were for MA 5 (10\%) vs. 7 (14\%), kappa 0.81 , and for MO 9 (18\%) vs 10 (20\%), kappa 0.81, respectively. For any type of migraine in control subjects, kappa was 0.77 .

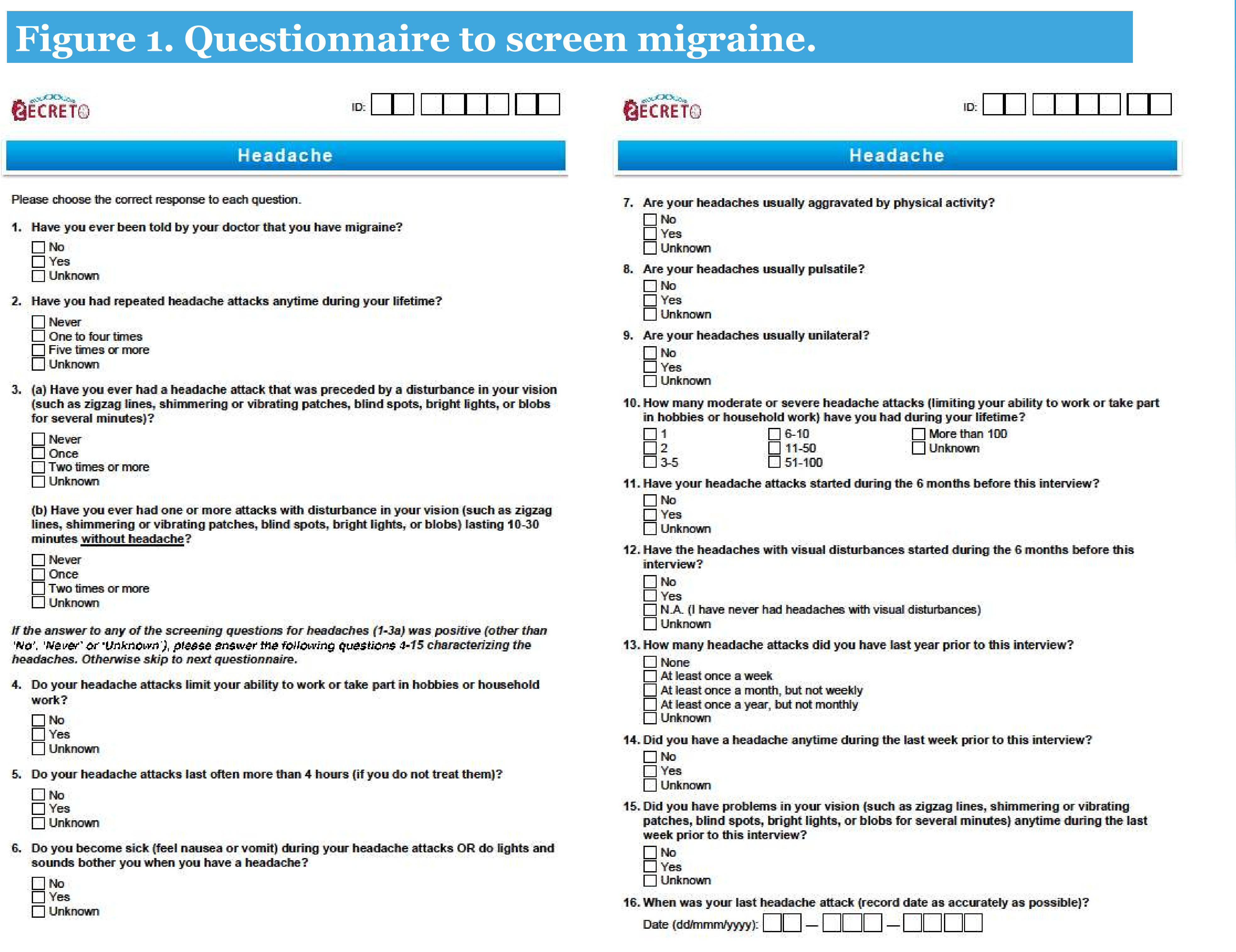

\begin{tabular}{|c|c|c|}
\hline \multicolumn{3}{|c|}{$\begin{array}{l}\text { Table 1. Selected comorbidities and physiological } \\
\text { characteristics in the } 50 \text { cryptogenic ischemic stroke } \\
\text { patients and } 50 \text { stroke-free control subjects. }\end{array}$} \\
\hline Study population characteristics & $\begin{array}{c}\text { Patients } \\
n=50\end{array}$ & $\begin{array}{c}\text { Controls } \\
n=50\end{array}$ \\
\hline Median age, years & $41(35-46)$ & $42(37-48)$ \\
\hline Female & $23(46)$ & $24(48)$ \\
\hline Migraine with aura, questionnaire & $22(44)$ & $5(10)$ \\
\hline Migraine with aura, interview & $22(44)$ & $7(14)$ \\
\hline Migraine without aura, questionnaire & $4(8)$ & $9(18)$ \\
\hline Migraine without aura, interview & $6(12)$ & $10(20)$ \\
\hline Vascular comorbidity* & $15(29)$ & $10(20)$ \\
\hline Current smoking & $13(26)$ & $10(20)$ \\
\hline Systolic blood pressure & $121( \pm 11)$ & $124( \pm 11)$ \\
\hline Diastolic blood pressure & $73( \pm 9)$ & $75( \pm 9)$ \\
\hline Heart rate & $68( \pm 11)$ & $66( \pm 11)$ \\
\hline Physical inactivity & $6(12)$ & $6(12)$ \\
\hline Waist-to-hip ratio & $0.90( \pm 0.09)$ & $0.87( \pm 0.10)$ \\
\hline Excess alcohol use & $25(50)$ & $22(44)$ \\
\hline Right-to-left shunt found in TEE or TCD & $32(64)$ & $15(29)$ \\
\hline
\end{tabular}

Data are expressed as median (interquartile range), mean $( \pm \mathrm{SD})$, or $\mathrm{n}(\%)$.

*Vascular comorbidity includes any of hypertension, dyslipidemia, diabetes, coronary heart disease, veripheral arterial disease, or aneurysm.

\section{Conclusions}

Our migraine-screening questionnaire is valid to identify persons with MA and MO with an excellent agreement between the screening questionnaire and experienced clinician in both patients and healthy controls.

\section{References}

1. Putaala J, Metso AJ, Metso TM, et al Analysis of 1008 consecutive patients aged 15 to 49 with first-ever ischemic stroke: the Helsinki young stroke registry. Stroke. 2009;40:1195-203.

. Yesilot Barlas N, Putaala J, Waje-Andreassen U, et al. Etiology of first-ever ischaemic stroke in European young adults: the 15 cities young stroke study. Eur J Neurol. 2013;20:1431-9

Spector JT, Kahn SR, Jones MR, Jayakumar M, Dalal D, Nazarian S. Migraine headache and ischemic stroke risk: an updated meta-analysis. Am J Med. 2010;123:612-624.

4. Putaala J, Martinez-Majander N, Saeed S, et al. Searching for Explanations for Cryptogenic Stroke in the Young: Revealing the Triggers, Causes, and Outcome (SECRETO): Rationale and design. European Stroke Journal 2017 04/04; 2017/05:2396987317703210. 